\title{
A ENFERMAGEM NA ALEMANHA: ALGUMAS REFLEXÕES SOBRE SUA CONSTITUIÇÃO HISTÓRICA E O PROCESSO ATUAL DE PROFISSIONALIZAÇÃO
}

Maria Elisabeth Kleba*

KLEBA, M.E. A enfermagem na Alemanha: algumas reflexões sobre sua constituição histórica e o processo atual de profissionalização. Rev.latino-am.enfermagem, Ribeirão Preto, v. 4, n. 3, p. 117-133, dezembro 1996.

Neste artigo busco resgatar raízes da institucionalização da assistência à doença na Alemanha e da constituição da enfermagem como categoria profissional. Descrevo características do modelo assistencial alemão, situando a enfermagem enquanto profissão que sofre atualmente um processo de revisão em sua formação e em suas concepções para a prática. $A$ abertura de cursos em nível universitário e a introdução de concepções como holísmo e instrumentalização dos pacientes para seu auto-cuidado, abre novas perspectivas para a enfermagem alemã, ao mesmo tempo em que soma esforços na construção de novos caminhos para a enfermagem internacional.

UNTERMOS: enfermagem na Alemanha, constituição histórica, modelo assistencial

\section{APRESENTAÇÃO}

Em abril de 94 iniciei meu doutorado na Universidade de Bremen na Alemanha. Aproximadamente um ano após, tomei conhecimento do processo que vinha se consolidando nos últimos anos neste país: Escolas Superiores abrem espaço para a enfermagem (duas em Bremen) de tal forma que nos últimos quatro anos 17 cursos de Administração, Licenciatura ou Ciências de Enfermagem foram

* Docente da UNOESC-Campus Chapecó-SC, Mestre em enfermagem pela UFSC-SC, doutoranda pelo CNPq em Pedagogia Social na Universidade de Bremen-Alemanha 
iniciados no país. O fato me alegrou e surpreendeu ao mesmo tempo, pois, se por um lado novas perspectivas para a enfermagem estão sendo construídas, por outro lado o processo não está recebendo o devido reconhecimento ou interesse por parte da sociedade em geral ou se quer dos profissionais de saúde que, em grande parte, o ignoram.

Parece-me oportuno divulgar o processo que vive atualmente a enfermagem na Alemanha como forma de somar esforços nesta luta - que não é particular, pois poderá ter importantes conseqüências para a categoria como um todo - por melhores condições de trabalho, por conquista e reconhecimento de novas competências para a profissão $e$, conseqüentemente, melhoria da qualidade da assistência a saúde da população.

Para escrever o presente artigo busquei informações na literatura e fundamentei-me em entrevistas formais com profissionais de um hospital de Bremen e com um professor da Escola Superior de Bremen, além de participar de encontros e discussões sobre o processo. Diálogos informais com estudantes de enfermagem no intuito de apreender como vem sendo vivenciado e interpretado no cotidiano da assistência o processo atual de profissionalização, também se constituíram em fonte de informações.

\section{INTRODUÇÃO}

A Alemanha como país do primeiro mundo, é tido como modelo na prestação de serviços médicos. Dispondo de alta tecnologia em sua estrutura terapêutica transmite uma imagem de "estado de seguridade social" com alta capacidade de intervenção nos processos de saúde-doença de sua população. Mas a imagem que influência o desenvolvimento de modelos assistenciais em muitos países representa um sistema que hipervaloriza a técnica, o "saber científico" e impõe o poder da categoria médica sobre a saúde dos indivíduos. "Desumanização da medicina" é como pode ser caracterizado o longo processo de institucionalização da assistência em nosso mundo ocidental e é o que se percebe no cotidiano da prática profissional na Alemanha.

Em contrapartida, mais como questionamento e demonstração de insatisfação pessoal, um processo de resistência se denuncia em focos de discussão sobre a assistência atual. A enfermagem participa desta discussão como categoria que descobre novos caminhos para sua prática profissional. Com um grande contingente de seu pessoal envolvido em cuidados domiciliares à pacientes crônicos e idosos, a enfermagem preenche condições para afirmar-se na Alemanha como uma "profissão para a saúde", para o que necessita rever suas bases conceituais. 
Entretanto, raízes profundas de docilidade e submissão tornam o processo de profissionalização da enfermagem na Alemanha uma gestação dolorosa. Por um lado, percebe-se resistência de grande parcela da categoria que teme por sua situação pessoal. Por outro lado, outra parcela entende ser imprescindível a afirmação da enfermagem enquanto ciência e vem se engajando na construção de perspectivas para o futuro e na conquista de novos espaços políticos e institucionais.

\section{A INSTITUCIONALIZAÇÃO DA ASSISTÊNCIA}

A primeira forma de cuidado institucionalizado na Alemanha tem seu registro já no século primeiro d.C.. "Casas de Saúde" são então organizadas para o tratamento dos soldados em acampamentos da Legião Romana, a qual controlava grande parte da Europa na época. Entretanto, é através da Igreja, a partir do século III, que a consolidação da assistência, enquanto prática institucional, recebe seu definitivo impulso. Algumas ordens eclesiásticas, entre elas os Beneditinos e os "Cavaleiros da Virgem Maria" se organizam no intuito de prestar assistência a monges, pobres e viajantes. Estas ordens dispunham de quartos em seus mosteiros, construídos ao lado da capela, que deveriam servir tanto ao cuidado do corpo quanto ao da alma (PÜSCHEL, 197_, p. 4).

A relação entre assistência e misericórdia adquiriu um significado relevante, contribuindo não só para a consolidação da assistência como também da própria Igreja, que conquistava, assim, um maior espaço nas relações de poder político e controle social. A inda hoje a relação entre caridade $\mathrm{e}$ assistência, assim como os ideais de servir, exercem uma forte influência na enfermagem.

Apesar do cuidado domiciliar ser ainda predominante, o hospital passa a ser entendido enquanto estrutura imprescindível na prestação da assistência até finais do século XIX. Ao mesmo tempo, o Estado passa a desempenhar um novo papel na coordenação das relações sociais e assume o controle sobre o corpo de seus cidadãos através do controle de dados estatísticos, como nascimento e morte, e da organização de serviços médicos que lhe garantissem indivíduos saudáveis e produtivos.

Por outro lado, a profissionalização da medicina desencadeou um processo de mobilização da categoria no sentido de ampliar seu espaço de atuação social, impondo-se como serviço essencial e garantindo posição privilegiada no mercado de trabalho.

$\mathrm{Na}$ formação do sistema assistencial, os movimentos de operários desempenharam um papel decisivo, reivindicando assistência aos trabalhadores em caso de doença ou velhice e forçando para isto a criação de Caixas de Seguro. 


\section{A ASSISTÊNCIA À SAÚDE HOJE}

O modelo de assistência à saúde vigente atualmente na Alemanha pode ser caracterizado como um "sistema de seguridade em caso de doença"1 (Krankenversicherungssystem) e tem sua origem nas Instituições de "Auto-Ajuda", organizadas no início do século XIX pelos sindicatos, comunidades ou lgreja. A partir da estatização das Caixas de Seguro, no governo Bismark em 1883, o "Seguro de Saúde" ${ }^{2}$ passa a ser obrigatório e a participação dos trabalhadores e empregadores na gestão das mesmas passa a ser regulamentada pelo Estado. A idéia da mútua solidariedade vigora até hoje, ou seja, a contribuição individual é calculada com base no salário e independe dos gastos em caso de adoecimento.

Atualmente existem na Alemanha 1.153 Seguros de Saúde "oficiais" (gesetzliche Krankenkassen) $^{3}$ que cobrem $90 \%$ da população e $95 \%$ dos gastos em caso de doença e cerca de 50 Seguros de Saúde privados (ALBER et al., 1992, p.79). O sistema de seguridade está organizado em cinco estruturas principais: Seguro de Saúde (Krankenversicherung); Seguro para o Cuidado (Pflegeversicherung) ${ }^{4}$; Seguro para a aposentadoria (Rentenversicherung); Seguro de Acidentes (Unfallversicherung) e Seguro Desemprego (Arbeitsförderung - Arbeitslosenversicherung).

As funções de cada segmento do sistema de seguridade estão descritas a seguir (Fontes: BESKE et al., 1993, p.62-63 e SCHMIDT, 1994, p.55):

Seguro de Saúde

Ações para reconhecimento precoce de doenças

Financiamento no tratamento de doenças

Auxílio doença / Auxílio maternidade /Auxílio família / Auxílio

Funeral

Outros auxílios

\footnotetext{
${ }^{1}$ Os "Seguros de Saúde possuem na Alemanha autonomia gerenciar frente ao aparelho estatal, assumindo ações preventivas e subvencionando ações curativas. A expressão "seguridade para a doença" aparece em discussões atuais, as quais criticam o sistema vigente e referem não haver um "sistema de saúde" na Alemanha

${ }^{2}$ Passo a adotar o termo "Seguro de Saúde", pois o mesmo é utilizado no Brasil atualmente para denominar as caixas de seguro para assistência à doença. Considero, no entanto, tal termo inadequado, pois tais seguros se ocupam com a doença de seus clientes, e mesmo assim com restrições e não com a sua saúde. O termo "caxias de assistência, pensão e aposentadoria", conforme eram chamados as primeiras as primeiras formas institucionalizadas de seguridade no Brasil, seria mais adequado para a tradução do termo alemão

${ }^{3}$ Os "Seguros Oficiais" foram historicamente constituídos, tendo sua origem nos seguros criados para grupos específicos de trabalhadores ou profissionais. Assim persistem as estruturas organizadas em nível local regional, administradas por entidades de interesse público

${ }^{4}$ Este seguro, criado em 1994, entrou em vigor em abril de 95 e traz novas perspectivas para a enfermagem em nível ambulatorial, apesar de apoiar uma grande rede de ações leigas e o cuidado familiar. Sofre no momento intensa discussão e inúmeras críticas
} 
Seguro para Cuidados Pagamentos em caso de dependência de:

Cuidados com o corpo - higiene e excreção

Cuidados com alimentação - preparo e ingestão

Apoio na mobilização - levantar, deitar-se, despir e vestir roupas, caminhar, erguer-se, subir escadas, sair e voltar para casa

Cuidados com a habitação - compras, limpar, lavar, cozinhar

Seguro Aposentadoria Ações gerais para melhoria das condições de saúde da população assegurada

Ações de reabilitação

Aposentadoria para os aposentados e seus dependentes

Seguro Acidentes

Prevenção de acidentes

Ações de reabilitação

Aposentadoria para invalidez causada por acidentes (também aos dependentes)

Seguro Desemprego Aconselhamento para o trabalho

Intermediação para emprego

Apoio na formação para o trabalho

Ações de reabilitação para o trabalho

Apoio na conquista de vagas para o trabalho

Auxílio desemprego bem como outros auxílios na busca de emprego (Inscrição em concursos, p.e.)

Pesquisa de mercado de trabalho e emprego

A escolha pela forma de seguridade é determinada em lei específica. Entre outros critérios para o acesso à Seguro Estatal consta a renda: pessoas com alta renda podem possuir apenas Seguro Privado. Para os demais, paralelamente ao seguro obrigatório, é possível assegurar-se de forma privada.

A estrutura do Sistema de Saúde é organizada a partir da assistência hospitalar. A Alemanha dispõe de 3.045 Hospitais, com um total de 669.663 leitos, numa proporção de 106,9 leitos por 1.000 habitantes. Destes, 979 Hospitais, com um total de 105.783 leitos, são privados (15,8\% do total). Para a assistência ao idoso e o excepcional existem atualmente 8.048 Instituições, as quais dispõem de 605.516 vagas (BESKE et al., 1993).

Além da assistência hospitalar há uma vasta rede de assistência domiciliar profissionalizada $^{5}$, através da qual serviços de enfermagem e fisioterapia são oferecidos e são em grande parte financiados pelos Seguros de Saúde. A assistência financiada pelo Seguro para Cuidados é prestada geralmente por leigos - alguém da família, estudantes ou voluntários. A intenção de apoiar relações de solidariedade

\footnotetext{
${ }^{5}$ A assistência domiciliar é subjugada à assistência hospitalar, pois além de necessitar da prescrição e solicitação por parte de profissionais médicos é muitas vezes continuidade de um tratamento
} 
e reconhecer os serviços prestados por familiares aparece como justificativa da criação deste seguro que, no entanto, é questionado, pois favorece uma assistência segmentada ao invés de possibilitar o cuidado integral, holístico.

Postos de Saúde estão organizados sob a estrutura administrativa municipal e têm entre suas funções o exame médico do escolar, a educação para a saúde com o aconselhamento na gravidez, puericultura, alimentação e prevenção de vícios. $\mathrm{Na}$ estrutura assistencial os postos de saúde possuem um status marginalizado, sendo que um médico "comunitário" não pode prescrever medicação ao mesmo tempo que não tem acesso direto a equipamentos para diagnóstico terapêutico, o que, na concepção européia sobre assistência, Ihe confere um significado pejorativo.

A seguir são relacionados números de profissionais de saúde em atividade em 1990 (Fonte:. BESKE et al., 1993, p.173):

\begin{tabular}{lr}
\hline Profissionais & Números \\
\hline Profissionais de enfermagem/Parteiras & 574.000 \\
Médicos & 195.254 \\
Massagistas/Fisioterapeutas & 83.000 \\
Bioquímicos/Técnicos de Laboratório & 72.000 \\
Odontológico & 43.167 \\
Farmacêuticos & 36.476 \\
Assistentes de farmácia e dietética & 29.000 \\
"Práticos terapêuticos" & 7.000 \\
Auxiliares de consultório & 300.000 \\
\hline Total & 1.339 .895 \\
\hline
\end{tabular}

Diferentemente do Brasil, os profissionais médicos que trabalham nos hospitais têm seu contrato institucional por tempo integral. Após o término dos estudos, um médico deve "assistir" no hospital por um tempo determinado (em torno de 5 a 6 anos) dentro de uma determinada especialidade. Após este prazo e tendo cumprido um mínimo de ações (prescritas em catálogo próprio), deve realizar exame para que possa exercer a medicina enquanto profissional liberal. Pode então optar entre ter um consultório privado ou trabalhador no hospital. Com exceção dos "médicos-chefe", que podem atender pacientes privados em ambulatórios do próprio hospital, tendo assim uma fonte de renda extra, os demais médicos que trabalham em hospitais são assalariados.

Para assistência o assegurado pode escolher, dentre os conveniados, o profissional que deseja consultar ou do qual necessita um cuidado específico, seja médico, psicólogo ou dentista, cuja intervenção será posteriormente coberta pelo instituto no qual o mesmo estiver assegurado. Exames necessários são providenciados pelo profissional em seu consultório, clínica ou prescritos em internação hospitalar. Medicamento prescrito pelo médico é adquirido em farmácia 
e com algumas exceções, reembolsado posteriormente pelo seguro. A assistência de enfermagem ou de outros cuidados domiciliares deve ser prescrita por médico e solicitada junto à instituições organizadas para este fim.

Tais facilidades proporcionadas aos usuários ocasionam um hiper consumo dos serviços terapêuticos, de forma que os gastos com a estrutura assistencial têm sido um dos principais pontos de discussão quando se fala em políticas de saúde. Não poderia ser diferente num sistema que prioriza o aparato tecnológico e onde a seguridade social está construída sobre estruturas profissionalizadas e institucionais. A tendência das administrações hospitalares, compactuada pelo corpo clínico, é a de manter seus leitos ocupados, independente da real necessidade do paciente. Um leito sem paciente é calculado como prejuízo para a instituição. Tal prejuízo tem em sua base de cálculo um peso maior do que o possível prejuízo que o paciente possa sofrer no leito. É certo que a responsabilidade do médico sobre a doença do paciente e seu prognóstico recebe um grande peso frente aos direitos legais que o paciente usufrui no sentido de ter uma assistência de boa qualidade. Entretanto, bem mais que responsabilidade, o poder que a classe médica exerce sobre os indivíduos é um fator determinante das relações em saúde (ou melhor, doença). $E$ nisto a terapêutica na Alemanha não difere da realidade brasileira.

\section{A ENFERMAGEM NA ESTRUTURA ASSISTENCIAL}

\section{História da enfermagem na Alemanha}

A profissionalização da enfermagem acompanhou o desenvolvimento e a institucionalização da medicina na Europa. As primeiras ações de assistência institucionalizada de enfermagem foram desenvolvidas por homens - soldados romanos e monges da Igreja Católica. Aos poucos foram sendo engajadas as mulheres inseridas na estrutura da igreja, através de congregações religiosas fundada para este fim, e arregimentadas forças voluntárias nas comunidades para o cuidado domiciliar, principalmente aos doentes pobres e sem família (PÜSCHEL, 197_).

Entretanto, formas de assistência não institucionalizadas mantiveram um papel vital nas relações comunitárias. Curandeiras e práticas, entre elas as parteiras, sempre foram importante referência para a comunidade. Elas dispunham do conhecimento construídos através da prática e repassado tradicionalmente. Porém, com a consolidação da Igreja na Europa uma violenta perseguição foi desencadeada no sentido de erradicar práticas profanas de cuidado aos doentes. Juntamente com os médicos da época, uma nova ordem sobre o saber e a prática 
foi estabelecida, garantindo o poder e controle da Igreja. A medicina passou a ser ensinada em universidades, às quais somente homens tinham acesso. Mulheres até então ativas na assistência foram perseguidas como "bruxas possuídas pelo demônio", cruelmente e assassinadas (Frauen-Selbsthilfe-Laden apud KERSTAN \&WILDW, 1981).

Em 1452 foi fundada a primeira "Ordem para Parteiras" na Alemanha, a qual exigia uma formação de alguns anos e a aprovação em exame específico, para que fosse permitido praticar como parteira. Esta, no entanto, ficava sob as ordens do médico, devendo cumprir o que este determinava (ibidem).

Em 1782 foi fundada a primeira Escola para cuidados de enfermagem (Krankenwärterschule - "escola para assistentes de doentes") pelo médico Franz Anton May, em Mannheim. Em 1836, em Kaiserswerth, na província de Westfália, foi organizada pelo pastor Theodor Fliedner a primeira Escola de Enfermagem na qual um currículo teórico-prático deveria ser cumprido e um exame final era aplicado para a conclusão do curso. Esta escola foi visitada em 1850 por Florence Nightingale que em 1851 realizou ali um curso de formação de três meses. Vinte e cinco anos após sua criação existiam 28 Casas de Ensino (Mutterhäuser) na Alemanha. Estas escolas estavam integradas à estrutura hospitalar administrada por "irmãs" da Igreja Cristã (Diakonissen ou Ordensfrauen) e obedeciam a requisitos estabelecidos pela instituição. (PÜSCHEL, 197_, p. 9 e ROBERT-BOSCH-STIFTUNG, 1993, p.60)

Em 1997, primeiramente na Prússia, foi introduzida a Prova Estatal para o reconhecimento e a permissão do exercício da enfermagem. Para a realização de tal prova eram exigidas participação em curso próprio de um ano e a idade mínima de 21 anos. Seis anos após, a duração do curso passou a ser dois anos e a idade mínima para a realização da prova foi reduzida para vinte anos.

Desde o início a organização das escolas de enfermagem baseava-se no princípio de subordinação à categoria médica, ou seja, formação de mão de obra auxiliar e subalterna. Para tanto, a figura feminina era a que melhor se adaptava aos requisitos determinados ${ }^{6}$. Características como abnegação, humildade, obediência e sacrifício eram tidas então como naturais do sexo feminino, que deveria docilmente se submeter à ordens e ao controle médico (KÜPPER, $1994 \mathrm{E}$ KERSTAN \& WILDW, 1994). Neste sentido, os cursos de enfermagem eram dirigidos exclusivamente para mulheres, o que se pode constatar pelo nome dado às profissionais: Krankenschwester - "Irmãs dos doentes". Até recentemente a permissão para um homem freqüentá-las implicava em tratamento diferenciado (ROBERT-BOSCH-STIFTUNG, 1993). Segundo uma técnica de enfermagem, quando um homem participava como aluno em um curso de enfermagem, tinha sua

\footnotetext{
${ }^{6}$ Ainda hoje a profissão de enfermagem tem em seu quadro predominantemente mulheres. Segundo Küpper (1994, p. 27), 82\% entre enfermeiralos na Alemanha são mulheres. Em contrapartida, apenas 29\% entre médicos/as são mulheres (BESKE et al., 1993, p. 177)
} 
formação diferenciada e recebia inclusive algumas das aulas em classe separada (como por exemplo sobre o corpo humano). Suas funções deveriam ser auxiliares em serviços pesados ou em alguns cuidados aos pacientes do sexo masculino.

Considerando a posição social da mulher nos séculos XVIII e XIX, a enfermagem se constituía, então, como uma oportunidade de inserção da mulher no espaço social, fora do âmbito doméstico, e era vista como um avanço pelo movimento feminista da época (STEPPE, 1994, p.49).

A organização da categoria têm sua data histórica em 1903, quando Agnes Karll, Elisabeth Storp, Marie Cauer e Helene Mayer, com outras 33 enfermeiras, fundam a "Organização Alemã para a Profissão de Enfermagem" (Berufsorganisation der Krankenschwester) em Berlim, no intuito de proteger e aconselhar as enfermeiras sobre direitos e questões trabalhistas. Elas reivindicavam a melhoria das condições de trabalho, catastróficas nos hospitais da época (PLATE 1995, p.11).

Em 1966 foi introduzida, através de formas legais, uma nova Regulamentação para o ensino e para a realização do exame profissional. A duração de três anos, com o mínimo de 1.200 horas-aula, foi estabelecida como exigência para o reconhecimento do curso. A direção das Escolas de Enfermagem permanece até 1985 como sendo de competência médica. Somente após a reformulação da lei sobre a formação na enfermagem é prevista a possibilidade de uma profissional de enfermagem com formação para o ensino preencher este cargo ficando, porém na prática muitas vezes ainda subalterna ao profissional médico (ROBERT-BOSCH-STIFTUNG, 1993, p.26).

\section{A formação da enfermagem na Alemanha}

$\mathrm{Na}$ Alemanha a profissão de enfermagem está organizada em quatro áreas básicas: Enfermagem geral (Krankenschwester - krankenpflege); Enfermagem pediátrica (Kinderkrankenschwester - pflege); Enfermagem do Idoso (Altenpflegerin pflege); Enfermagem obstétrica / parteira (Hebamme - Entbindungspflege $)^{7}$. Para o exercício profissional é exigida a participação em curso específico numa das quatro áreas (organizados independentemente), com a duração de três anos e a aprovação em exame realizado pelo Estado. A formação é a nível técnico (como um nível secundário) e é oferecida pêlos hospitais onde os alunos realizam seus estágios práticos ao mesmo tempo em que são utilizados como mão de obra ${ }^{8}$.

\footnotetext{
${ }^{7}$ A classificação das parcerias dentro da categoria enfermagem não é consenso na Alemanha. Legal e institucionalmente elas possuem mais autonomia e reconhecimento - na assistência ao parto normal, p.e.; é obrigatório a presença da parteira e não do médico. Por isto muitas vêem a inclusão na categoria como rebaixamento de status. Por outro lado, a necessidade de revisão dos currículos, a possibilidade de ascensão de estudo universitário e a articulação com entidades internacionais aparecem como novas perspectivas e reúne-as na discussão e construção de interesses e identidade comuns

${ }^{8}$ Os alunos recebem remuneração mensal equivalente a aproximadamente um terço do salário inicial da categoria
} 
Num segundo nível encontram-se Auxiliares de Enfermagem (Krankenpflegehelferin - helfer) cuja formação é de um ano. A oferta de tais cursos é cada vez menor e com a discussão atual sobre a necessidade da melhoria na capacitação profissional a tendência é sua extinção (em Bremen tal curso já não tem oferecido desde 1985).

As aulas são, em grande proporção, ministradas por profissionais da área médica. Segundo as enfermeiras entrevistadas, apesar de participar do corpo docente, falta à enfermagem um preparo didático suficiente para poder garantir na formação as especifidades inerentes à profissão, no que se refere aos aspectos complementares da técnica. A insatisfação com a qualidade do ensino é fortemente manifestada por muitos profissionais que referem a falta de uma base teórica fundamentada em questões específicas da enfermagem e o direcionamento da formação para uma prática de subordinação ao profissional médico, como grandes fatores de estagnamento e desvalorização profissional.

Há alguns anos a profissão enfrentou uma crise onde a procura por vagas em seus cursos diminuía progressivamente. Na Escola de Enfermagem de um Hospital em Bremen, por exemplo, de 458 inscrições (para 20 vagas) realizadas em 1986, apenas 123 foram registradas em 1991. Procurando superar a crise, a Associação Alemã para a Enfermagem (Deutscher Berufsverband für Pflegeberufe - DBFK) e a Associação dos Hospitais (Krankenhaus-gesellschaft DKG) articularam ampla campanha para melhorar a imagem da profissão e tornála atrativa a possíveis candidatos. Nesta campanha foram acentuadas conquistas recentes da categoria, tais como, jornada flexível de 38,5 horas semanais e a melhoria dos vencimentos.

Após os três anos de formação técnica, muitos profissionais participam de cursos de aperfeiçoamento, sendo que para algumas especialidades e para atividades como ensino e direção é exigida uma formação complementar. Tal formação pode durar três meses a dois anos, quando o aluno deve freqüentar semanalmente em turno de 4-8 horas de aula teórica e realizar algumas provas dentro de uma especialidade.

Algumas iniciativas no sentido de abrir espaços para a enfermagem na formação superior na Alemanha ao longo deste século são referidas na literatura. Em 1912, cinco anos depois da iniciativa nos Estados Unidos, começa a ser desenvolvida em Leipzig uma proposta para o ensino superior de enfermagem que com o início da primeira guerra mundial, não pode ser efetivada. Em Heidelberg, com o apoio da Fundação Rockefeller, e em Berlim (ocidental) são organizados cursos para a enfermagem que, no entanto, não foram assumidos pelas Universidades enquanto curso regular. Na ex-Alemanha Oriental, entretanto, três cursos foram iniciados ainda previamente à reunificação das duas Alemanhas em 1989. Em 1963 é iniciado na Humbold Universität de Berlim (oriental) o Curso de Pedagogia Médica (Medizinpädagogik), o qual em 1991 sofre uma reformulação e tem alterado sua nomenclatura para Pedagogia de Enfermagem (Pflegepädagogik). Em 
1982 é organizado na mesma Universidade o Curso de Enfermagem (Krankenpflege), destinado a profissionais da prática e é desenvolvido (ainda hoje) sob modalidade de formação complementar à prática, ou seja, o aluno mantém sua atividade e participa das aulas teóricas de forma integrada. Anteriormente à reunificação das Alemanhas o acesso aos referidos cursos era restrito à profissionais em atividade e indicado por instituições do Sistema de Saúde. Para o último curso era necessária ainda a indicação do médico distrital. Atualmente ambos os cursos são freqüentados em cerca de $60 \%$ por estudantes provenientes de Estados da ex-Alemanha Ocidental. Em 1988 a Universidade Martin-Luther, em Halle, iniciou o Curso de Pedagogia Médica, também com formação complementar para profissionais em atividade na enfermagem. (ROBERT-BOSCH-STIFTUNG, 1993, p. 31, 32 e 93, 94)

Estimulada pela crescente discussão sobre a necessidade de melhoria na formação de criação de oportunidades de ascensão profissional, Escolas Superiores (Hochschulen e Universidades) em 17 cidades da Alemanha abriram cursos na área de Enfermagem.

Desta forma abrem-se novas perspectivas para a profissão, ampliando-se seu espaço político e social. Até o momento a formação universitária tem buscado assessoria principalmente na Holanda e Estados Unidos, através de docentes, teorias e perspectivas de articulação no desenvolvimento das práticas e estágios. A meta, porém, é desenvolver teorias próprias, baseadas na realidade local.

\section{NOVOS DESAFIOS PARA A ENFERMAGEM NA ALEMANHA}

Dois temas aparecem com ênfase nas discussões sobre a enfermagem atualmente na Alemanha: (1) a questão da qualificação profissional, onde se acentuam a necessidade de melhoria e reestruturação dos cursos de formação e a abertura de novas oportunidades de ascensão para a categoria; e (2) a necessidade de uma revisão conceitual para a prática da enfermagem, onde o conceito de medicina e cuidado holístico predominam.

A questão da qualificação profissional tornou-se urgente a partir da organização da Comunidade Comum Européia. A formação na Alemanha, até então em nível técnico, deveria ser revista, e estruturas de ensino de países como Inglaterra, Holanda, Países da Escandinávia e U.S.A. se constituíram em modelos de referência ${ }^{9}$.

\footnotetext{
${ }^{9}$ Apesar de não participar da Comunidade Européia, os EUA exercem grande influência nas discussões em saúde e são referência na formulação de novas perspectivas para a prática de enfermagem
} 
Na Alemanha o ensino superior é organizado em duas estruturas, ou seja, nas Escolas Superiores, onde a formação é dirigida a um ensino mais prático e nas Universidades, onde o ensino busca desenvolver aspectos mais intelectualizados. Seguindo esta tendência, 14 Escolas Superiores oferecem na área de enfermagem cursos de Gerência, Administração e Licenciatura, enquanto três universidades abriram cursos de Ciências da Enfermagem, com a idéia de manter articulados ensino, pesquisa e prática. Para ser admitido em tais cursos, o candidato deve ter formação e pelo menos dois anos de prática na área. Nas Universidades, no entanto, um percentual de $25 \%$ pode ser preenchido por outros candidatos, os quais devem freqüentar um ano de disciplinas básicas antes de começar o curso propriamente dito. Esta seleção é justificada como forma de priorizar o acesso de profissionais que estão atuando na enfermagem e que, até o momento, não tinham possibilidade de ascensão profissional.

Muitas questões estão em aberto na formação acadêmica, tais como currículos, conteúdos programáticos e estágios, gerando grande insegurança entre os estudantes quanto ao futuro profissional. Como o foco central dos cursos é voltado para a administração, o ensino ou pesquisa, as disciplinas se concentram nestas áreas e, apesar de contemplarem conteúdos como as teorias de enfermagem, não prevêem a prática assistencial enquanto conteúdo programático. Apenas um curso, organizado na Faculdade de Medicina da Humbold Universität em Berlim, prevê uma concentração na área de ciências biológicas, incluindo conteúdos como anatomia, fisiologia, medicina preventiva e prática de enfermagem na assistência ambulatorial e hospitalar ((ROBERT-BOSCH-STIFTUNG, 1993, p.260). Desta forma os cursos oferecidos pelas Escolas Superiores estão organizados dentro de diferentes departamentos tais como economia, ciências sociais, ciências da educação, entre outros).

A criação dos cursos universitários implica na reformulação da estrutura de formação técnica, cujos professores até então, diferentemente dos outros cursos profissionalizantes, têm sua formação fora da estrutura universitária. Este processo está agora em discussão e não tem ainda perspectivas concretas uma vez que se imbrica com estruturas institucionais e políticas. Um grande esforço da categoria se faz necessário no sentido de vencer inseguranças e medos pessoais e somar esforços na construção de novos espaços e novas relações profissionais e interprofissionais.

Algumas idéias em pauta referem-se à necessidade de desvincular os cursos das instituições assistenciais, possibilitando maior autonomia na formação e descaracterizando-os como fornecedores de mão de obra barata, e à integração dos diferentes cursos na parte teórica, com um currículo comum de dois anos e a divisão por especialidades no último ano. Também a necessidade de maior embasamento teórico, prévio ao estágio prático, é apontada como fundamental.

Em relato de pesquisa sobre a situação do ensino de enfermagem realizada entre 89-90 em Berlin, são referidos três pontos básicos para garantir sua melhoria: 
(1) competência técnica: para tal o ensino deve viabilizar a tradução da teoria do cotidiano da enfermagem, instrumentalizando sua intervenção; (2) competência individual: deve ser levados em consideração valores, experiências e conhecimentos dos alunos, quando de sua instrumentalização para a tomada de decisões e para prática cotidiana; (3) competência coletiva: através do trabalho em equipe deve ser estimulada a capacidade de comunicação e cooperação necessária ao bom desempenho profissional. Observação e diálogo são princípios vitais para a enfermagem (ALTHOFF, 1995, p.24).

Para a formação na enfermagem vários teóricos são apontados como referência, entre eles, Klafki, que defende a necessidade de um ensino voltado para o desenvolvimento da autodeterminação, solidariedade e capacidade de decisão conjunta. Segundo ALTHOFF (1995, p.24), Klafki aponta como objetivos essenciais do ensino a competência, autonomia e solidariedade. A teoria de auto-ajuda de Orem também é referida como importante fundamentação para a prática da enfermagem, uma vez que esta desempenha um papel cada vez mais importante no cuidado ao paciente crônico e idoso (ibidem).

\section{A ENFERMAGEM EM BUSCA DE UMA PRÁTICA HOLÍSTICA}

No relatório da fundação Robert Bosch "Considerações sobre a necessidade superior para a administração em ensino da enfermagem", os autores referem a importância da enfermagem na garantia de um tratamento integral e contínuo, pois esta é a única profissão até a atualidade permanece generalista em sua prática, frente aos outros profissionais da área de saúde, principalmente dentro do espaço hospitalar (ROBERT-BOSCH-STIFTUNG, 1993, p. 64).

Inúmeros autores ${ }^{10}$ referem às ações integrais na assistência como prática inerente da enfermagem, que deve ser recuperada a melhor qualificada. O paciente deve ser entendido e abordado sob a ótica da totalidade numa perspectiva holística (Ganzheitlichkeit). Idéias como garantia de voz ou reconhecimento e apoio às capacidades do paciente são palavras de ordem no discurso atual da enfermagem.

Seguindo este paradigma algumas iniciativas são implementadas pela enfermagem, que busca dividir os serviços de forma alternativa nas unidades hospitalares, ou seja, não mais as ações são distribuídas entre a equipe, mas sim a equipe divide-se entre os pacientes. Cada membro tem sob seus cuidados alguns pacientes, buscando contemplar o conjunto das necessidades individuais e prestar uma assistência holística.

${ }^{10}$ Cito aqui CLAUDIA BISCHOFF e HILDE STEPPE as quais são referidas em outros trabalhos 
A dificuldade de traduzir a teoria em prática deve se à fatores extrínsecos e intrínsecos à enfermagem. Primeiramente ela é uma profissão integrada ao conjunto de praticas sociais, recebendo destas influências determinantes, tais como a submissão a controles e saberes "superiores", que definem o que a mesma deve e pode fazer. Por outro lado, como uma profissão majoritariamente feminina, a enfermagem ainda não tem conseguido romper suas raízes servis e assumir-se enquanto apta a formular seus próprios conceitos, redimensionando a profissão integrando-se na equipe de saúde de como parte da mesma e não mais a ela subalterna ${ }^{11}$.

O conceito de totalidade sob a concepção da medicina holística deve ser pensado em conjunto com outras categorias dentro do processo atual de crítica à medicina cartesiana. Porém, a enfermagem possui características próprias e necessita definir em sua dimensão o significado que o holísmo adquire para sua prática.

Para BISCHOFF (1994, p. 50) é necessário que a enfermeira ${ }^{12}$ se percebam como seres normais, com erros, dúvidas, necessidades, esperança e possibilidades. A enfermagem deve despedir-se do mito de "super-mãe", pronta a aceitar e fazer tudo, da figura de Mártir das relações sociais, a qual não pode nada transformar e tudo suporta... A partir daí pode construir novos caminhos, criando alternativas e desenvolvendo métodos próprios.

Aqui a concepção holística é a que melhor pode fundamentar a prática de enfermagem, que se aproxima cada vez mais do conceito de saúde-doença da OMS, na medida que amplia sua atuação junto à pacientes crônicos, idosos e saudáveis

${ }^{11} \dot{E}$ interessante observar como fatores culturais podem determinar concepção sobre "ser respeitado como membro da equipe". Na Alemanha é comum o tratamento impessoal em relações profissionais. Assim o "Sr." E "Sra" acrescido pelo sobrenome é o tratamento convencional. Neste sentido, uma entrevista refere como "inferiorização" na equipe, o fato de serem as enfermeiras tratadas por seu primeiro nome por outros profissionais e pelos clientes, enquanto médicos são chamados por "Doutor + o respectivo sobrenome". Apesar de chegar a $70 \%$ o percentual de médicos que realizam doutorado na Alemanha, o tratamento diferenciado pode significar o real distanciamento entre as categorias e a representação dos espaços dentro da hierarquia institucional

12 Existe atualmente uma discussão sobre como serão chamados os profissionais de enfermagem com formação superior na Alemanha. O nome Pflegewissenschaftler (cientista de enfermagem) vem sendo adotado para referir-se à profissionais de outros países com esta formação neste país é semelhante à formação no Brasil, ou seja, voltada para a prática, e não como está sendo atualmente organizada na Alemanha, portanto, a nomenclatura "enfermeira/o" para traduzir o termo "Krankenschwester/pflege" que designa o profissional formado em nível técnico na Alemanha. Utilizo este termo, no entanto, para traduzir a idéia da autora que se refere ao conjunto de profissionais de enfermagem 
(puericultura, obstétrica e puerpério). Em contrapartida ao profissional médico, que têm sua ação cada vez mais concentrada na doença em seu momento agudo, a enfermagem desenvolve práticas no sentido de assisti ao indivíduo no seu cotidiano, muitas vezes em seu domicílio, envolvendo-o e a seus familiares ou vizinhança em seu auto-cuidado.

A medicina holística que têm como foco central o ser humano na compreensão e tratamento da doença pode dar o suporte necessário à enfermagem. Nesta concepção, a natureza não é vista como o agente causador de maléficos, que precisa ser combatido a qualquer custo, mas sim, como um meio propiciador da vida, no qual o indivíduo deve-se instrumentalizar em busca de seu equilíbrio. Nesse sentido a enfermagem pode auxiliar na instrumentalização do indivíduo, que deve assumir a responsabilidade e o controle sobre a sua vida. Não se podem ignorar aqui as forças sociais que impõe normas e valores e que têm favorecido um modo de viver doentio e destrutivo. Mas acima de tudo é necessário reconhecer o indivíduo enquanto capaz de pensar e reagir. Sob está ótica a enfermagem vem defendendo atitudes como apoiar o paciente em busca de sua autonomia e tomar o paciente "falante", o que demanda uma renúncia de poder individual e uma nova postura profissional.

Para enfermagem são necessários novos objetivos e perspectivas profissionais, não só ascensão profissional, mas, acima de tudo, na reformulação de sua prática profissional. Mas é necessário haver disposição para um primeiro impulso, sobre o qual a categoria possa depositar confiança e disposição para alegrar-se a cada pequeno passo, cada pequeno avanço conquistado no cotidiano da prática.

A enfermagem na Alemanha, como em tantos outros países, está buscando repensar sua condição enquanto profissional de saúde (no verdadeiro sentido). Demonstra assim sinais de coragem. Coragem para rever o velho e imaginar o novo. Coragem para reconhecer suas limitações e experimentar novos caminhos da realização da prática.

\section{NURSING IN GERMANY: SOME REFLECTION ABOUT ITS HISTORY AND ACTUAL NURSING PROFESSION}

In this article I outline some roots of the institutionalization of the assistance for illness in Germany and the arise of nursing as a profession. I describe characteristics of the German assistance model and situate nursing as a profession, specially its formation and conceptions pf its practice. The opening of university courses and the introduction of 
concepts like holism enabled patients to take care of themselves opening new perspectives for German nursing and stimulating the creation of new ways for nursing in the world.

UNITERMS: nursing in Germany, historical constitution, assistance model

\title{
LA ENFERMERÍA EN ALEMANIA: ALGUNAS REFLEXIONES SOBRE SU CONSTITUCIÓN HISTÓRICA Y EL PROCESO ACTUAL DE PROFESIONALIZACIÓN
}

\begin{abstract}
Con este artículo rescatar raíces de la institucionalización de la asistencia a la enfermedad en Alemania y la constitución de la enfermería como categoría profesional. Describió características del modelo asistencial Aleman, situando la enfermería en cuanto a la profesión que sufre en la actualidad un proceso de revisión en su formación y de sus conceptos para la práctica. La apertura de cursos en el nivel universitario y la introducción de conceptos como holismo y instrumentalización de los pacientes para su auto-cuidado, abre nuevas perspectivas para la enfermería Alemana, al mismo tiempo suma esfuerzos en la construcción de nuevos caminos para la enfermería internacional.
\end{abstract}

TÉRMINOS CLAVES: enfermería en Alemania, constitución histórica, modelo asistencial

\section{FONTES CONSULTADAS}

01. ALBER, J.; BERNARDI-SCHENKLUHN, B. Westeuropäische Gesundheitssysteme im Vergleich. Frankfurt am Main/New York: Campus, 1992

02. ALTHOFF, R. Patientenorientierte Reform der Krankenpflegegeausbildung. Pflegepedagogik, Basel, n.1, p.22-27, 1995.

03. BESKE, F.; BRECHT, J.; REINKEMEIER, A.M. Das Gesundheitswesen in Deutschland. Köln: Dt. Ärzte Verlag, 1993.

04. BISCHOFF, C. Ganzheitlichkeit in der Pflege. MABUSE, Frankfurt/M, v. 19, n. 91, p. 37-41, ago-set, 1994.

05. BISCHOFF, C.; BOTSCHAFTER, P. Über die Bedeutung einer wissenschaftlichen Lehrerqualifikation für die Pflegeberufe. Die Schwester - Der Pfleger: Fachzeitschrft für Krankenpflege, Melsungen, v. 29, n. 9, p. 800-805, set. 1990. 
06. FRAUEN-SELBSTHILFE-LADEN "IM 13. MOND". Hexen, Hebammen, Frauenärzte. In:__ KERSTAN, Birgit; WILDW, Helga (org). Selbstbestimmung in der Offensive: Frauenbewegung Selbsthilfe Patientenrechte. Berlin: Verlagsgesellschaft Gesundheit, 1981. p. 116-131.

07. KÜPPER, G. Karriere von Frauen in der Krankenpflege. Die wissenschaftliche Zeitschrift für Pflegeberufe, v.7, n.1, Mär., 1994.

08. PLATEN, H. Autopferung ist nicht die beste Pflege. Die Tageszeitung. Quarta, 22 mar., 1995. P.11.

09. PÜSCHEL, E. Tabellarische Darstellung der Geschichte der Krankenpflege für Kinderkrankenschwestern und-schlülerinnen. Bochum, 197_. (Caderno patrocinado pela ALETE)

10. ROBERT-BOSCH-STIFTUNG. Pflege braucht Eliten: Denkschrift zur Hochschulausbildung für Lehr und Leitungskräfte in der Pflege; mit systematischer Begründung und Materialien. 4. Auflage. Gerlingen: Bleicher Verlag, 1993. (Beiträge zur Gesundheitsökonomie;28)

11. ROSEN, G. Die Entwiclung der sozialen Medizin. In: DEPPE, Hans-Ulrich; REGUS, Michael. Seminar: Medizin, Gesellschaft, Geschichte. Frankfurt a. M.: Suhrkamp, 1972. P.75-130.

12. SCHMIDT, M. Guter Rat zur Pflegeversicherung. München: DTV, 1994.

13. STEPPE, H. Pflege im Umbruch. Zeitschrift im Gesundheitswesen - MABUSE, Frankfurt/M, v.19, n.90, jun-jul. 1994.

14. WEINRICH, R. The federal Republic of Germany. In: QUINN, Dame Sheila; RUSSEL, Susan. Nursing: the European Dimension. Oxford: Scutari Press, 1993.

\section{FONTES DE DADOS COMPLEMENTARES}

Entrevista com 6 enfermeiras e um médica do Diakonisenkrankenhaus e um professor da escola superior de Bremen, fev.-maio de 1975.

Anotações nos encontros:

- Seminário de informações dos estudantes dos cursos internacional para a administração em enfermagem, promovido pela escola superior de Bremen, em 9 de maio de 1995;

- Seminário "ciências de enfermagem" - desenvolvimento de uma prática associada à ciência, promovido pela universidade de Bremen, em 22 de maio de 1995.

- IV Encontro de Estudantes de Ciências de Enfermagem e da Saúde: "Visões entre o futuro e a realidade", promovido pela escola superior de Frankfurt am Main, de um ponto 1. a 4 de novembro de 1995. 